\title{
A ÁREA RURAL CONSOLIDADA E A ANISTIA AOS DANOS AMBIENTAIS NO CÓDIGO FLORESTAL BRASILEIRO: Retrocesso Legitimado Pelo STF
}

\author{
http://dx.doi.org/10.21527/2176-6622.2018.50.102-114
}

Recebido em: 18/7/2018

Aceito em: 17/10/2018

\section{Beatriz Souza Costa}

Doutora e mestre em Direito Constitucional pela UFMG. Professora na Pós-Graduação em Direito Ambiental e Desenvolvimento Sustentável da Escola Superior Dom Helder Câmara e pró-reitora de Pesquisa da ESDHC. biaambiental@yahoo.com.br

Lara Maia Silva Gabrich

Mestranda em Direito Ambiental e Desenvolvimento Sustentável pela Escola Superior Dom Helder Câmara. Professora do Centro Universitário FIPMoc - UNiFiPMoc. Pesquisadora integrante do grupo A Mineração e o Desenvolvimento Sustentável nos Tribunais. laragabrich@gmail.com

\section{RESUMO}

Este artigo tem como objetivo analisar a decisão do Supremo Tribunal Federal nas Ações Diretas de Inconstitucionalidade (ADIs) 4.902 e 4.937, especificamente quanto aos artigos 3o, IV; 7으, §3; 17, §3; 59, §§ 4ㅇe 5ㅇ; 61-A, 61-B, 61-C e 63 da Lei n. 12.651/2012, Código Florestal. Por meio de pesquisa jurídico-teórica, qualitativa, procedimento de raciocínio dedutivo, técnica de pesquisa doutrinária, bibliográfica e jurisprudencial, inicialmente, contextualizou-se os dispositivos que autorizam a área rural consolidada, bem como a anistia de multas, a isenção de desmatamentos irregulares, a imunidade à fiscalização e à consolidação dos danos ambientais, com marco legitimatório a data de 22 de julho de 2008, inexistindo pertinência jurídica concebível. Concluiu-se ser questionável a decisão quanto a seus critérios e por desconsiderar, na sociedade de risco e suas consequências, a máxima do desenvolvimento sustentável em resolução ofensiva à vedação ao retrocesso socioambiental.

Palavras-chave: Código Florestal. Vedação ao retrocesso. Desenvolvimento sustentável. Anistia. Dano ambiental. Área rural consolidada.

\section{THE CONSOLIDATED RURAL AREA AND THE ANALYSIS OF ENVIRONMENTAL DAMAGES IN THE BRAZILIAN FOREST CODE:} \section{STF LEGITIMIZED REGRESSION}

\section{ABSTRACT}

The purpose of this article is to analyze the decision of the Federal Supreme Court in the Direct Actions of Unconstitutionality (ADIs) 4902 and 4937, specifically regarding the articles, articles 3, IV; 7, §3; 17, §3o; 59, §§ 4 and 5; 61-A, 61-B, 61-C and 63 of Law no. 12.651/2012, Forest Code. By means of a research legal-theoretical, qualitative methodology, procedure of deductive reasoning, technique of doctrinal, bibliographical and jurisprudential research, initially, contextualized the devices, which authorize the consolidated rural area, as well as the amnesty of fines, exemption of illegal deforestation, immunity from inspection and consolidation of environmental damage, with a legitimating framework dated July 22, 2008, without any conceivable juridical relevance. It was concluded that the decision is questionable, as it does not consider the society at risk and its consequences for sustainable development in a resolution offensive to non-regression socio-environmental.

Keywords: Forest Code. Non-regression. Sustainable development. Amnesty. Environmental damage. Consolidated rural área

\section{SUMÁRIO}

1 Introdução. 2 A Lei 12.651/12 (Código Florestal) e as Ações Diretas de Inconstitucionalidade 4.902 e 4.937. 3 A Discutível Decisão do STF e a Desproteção do Meio Ambiente. 4 A Proteção Jurídica do Meio Ambiente: Aspectos Conceituais e Natureza Jurídica. 5 Os Princípios Constitucionais Ambientais: Teorias sobre Princípios e Regras, o Desenvolvimento Sustentável e o Retrocesso Socioambiental. 6 Considerações Finais. 7 Referências. 


\section{INTRODUÇÃO}

A Lei n. 12.651/2012, Código Florestal Brasileiro, trouxe algumas inovações e, desde antes de sua vigência, vem sendo objeto de polêmicas e debates entre especialistas, sociedade civil e cientistas do Direito, por polarizar interesses econômicos de ruralistas em detrimento da proteção do meio ambiente, defendida pelos ambientalistas.

O texto final aprovado, tal qual defenderam os ruralistas, traz pontos juridicamente controversos e questionáveis, o que ensejou Ações Diretas de Inconstitucionalidade - ADIs 4.901, 4.902, 4.903, 4.937 - sob alegações de que vários dispositivos contrariam a Constituição da República Federativa do Brasil de 1988 (CRFB/88), reduzindo a proteção já garantida pelo Código Florestal anterior e demais legislações esparsas, revogadas pelo Novo Código Florestal (NCF).

A ADI 4.902, especificamente, partiu da Procuradoria Geral da República e, fundamentada nos artigos 102 , I, a, p, artigo 103, VI da CRFB/88, pleiteou abertura do controle abstrato de constitucionalidade, buscando a declaração da inconstitucionalidade de dispositivos da Lei n. 12.651/12, que não se coadunariam com os artigos 5o, 186, I e II e 225, da CRFB/88, exatamente por diminuírem o padrão de proteção ambiental e, mais, ainda, extinguirem espaços territoriais especialmente protegidos. Já em 4 de abril de 2013 o Partido Socialismo e Liberdade (Psol) ajuizou, com a mesma finalidade, a ADI no 4.937.

Assim, em 28 de fevereiro de 2018, após julgamento do Tribunal Pleno, o STF julgou procedente em parte as ADIs. Pela decisão, nenhum dispositivo foi considerado inconstitucional, mas apenas expressões foram suprimidas e, em outros casos, deu-se interpretação conforme a Constituição. A própria tramitação das ADls, que atacam 58 dos 84 artigos do texto legal, foi complexa, contando, inclusive, com a realização de Audiência Pública para participação de expositores técnicos de diversos segmentos afins às questões ambientais, econômicas e jurídicas. Por essa razão, mesmo após a decisão do STF, que privilegiou interesses econômicos em detrimento da proteção ambiental, torna-se necessário lançar um olhar crítico para alguns dispositivos específicos, uma vez que os artigos 3으, IV; 7으, §3; 17, §3ㅇ; 59, §§ 4ㅇe 5우 61-A, 61-B, 61-C e 63, especificamente, podem materializar danos ambientais cujas consequências ainda são desconhecidas, o que legitima a degradação e desproteção ambiental, configurando retrocesso ambiental.

O objetivo geral, portanto, é analisar a decisão do Supremo Tribunal Federal nas Ações Diretas de Inconstitucionalidade (ADIs) 4.902 e 4.937, especificamente quanto aos artigos 3ㅇ, IV; 7ㅇ, §3; 17, §3ㅇ; 59, §§ 4응 e 5o; 61-A, 61-B, 61-C e 63 da Lei n. 12.651/2012, Código Florestal.

Para tanto, desenvolveu-se uma pesquisa com a metodologia jurídico-teórica, qualitativa, e procedimento de raciocínio dedutivo, utilizando-se de técnica de pesquisa doutrinária, bibliográfica e jurisprudencial para atingir seus objetivos, partindo-se da ideia de que a decisão das ADIs quanto aos dispositivos especificamente analisados é questionável, por desconsiderar a intangibilidade do direito fundamental ao meio ambiente equilibrado, prejudicando o pacto intergeracional, bem como se apresenta em desconformidade com a vedação ao retrocesso socioambiental, uma vez que, ignorando a sociedade de risco, possibilita a materialização de danos ambientais ainda desconhecidos.

Inicia-se a discussão contextualizando a Lei n. 12.651/2012 e as ADls 4.902 e 4.937, que, por critério de delimitação de objeto de pesquisa, abarcam os dispositivos analisados. Nessa intenção, detalha-se os artigos a que as ADIs se referem, analisando os pontos de crítica e possíveis problemas jurídicos de cada um deles. $\mathrm{Na}$ sequência, trabalha-se a decisão do Tribunal Pleno do STF e suas implicações, considerando a Audiência Pública realizada como parte do procedimento das ações e, isso posto, faz-se a análise a partir da natureza jurídica do direito ao meio ambiente ecologicamente equilibrado, sob as perspectivas das teorias sobre princípios e regras, e dos princípios do desenvolvimento sustentável e o retrocesso socioambiental. Por fim, nas considerações finais, aborda-se os pontos que merecem atenção na decisão do STF analisada quanto à discussão proposta.

\section{A LEI 12.651/12 (CÓDIGO FLORESTAL) E AS AÇÕES DIRETAS DE INCONSTITUCIONALIDADE 4.902 E 4.937}

A Lei n. 12.651/2002, que traz o Código Florestal brasileiro, aprovada pelo Congresso Nacional em 25 de maio de 2012, é, desde seu projeto, uma celeuma jurídica quanto à interpretação e aplicabilidade, mas, mais ainda, quanto a sua constitucionalidade. A revogação a todo custo do Código Florestal de 1965 (Lei n. 
4.771/65) é de tamanha inconstância legislativa que já nasceu modificado pela Lei n. 12.727/2012, em um curto tempo de seis meses, ensejando, ainda, a regulamentação pelo Decreto n. 7.830/12 que trata do Cadastro Ambiental Rural (CAR) e dos Programas de Regularização Ambiental (PRA). Além disso, foi de imediato atacado por Ações Diretas de Inconstitucionalidade que se fundamentaram justamente na incompatibilidade com a proteção ambiental constitucional, porquanto, reduzindo a proteção maior já garantida pela legislação anterior, legitima danos ambientais e inviabiliza o pacto intergeracional. Não obstante,

o Texto Legal comentado é ruim como técnica jurídica, inseguro e falho em seus conceitos, excessivamente abrangente e, portanto, contraditório. Produzido para ser uma lei geral, é lei detalhista, minuciosa, excessiva, pecando $a b$ initio, por ultrapassar a competência federal estabelecida pelo artigo 24 de nossa Constituição, que é a de produzir leis gerais. [...] Enfim, a Lei no 12.651, de 2012, é um anticlímax (ANTUNES, 2014, p. 2).

As contradições já são vislumbradas em seu artigo 1ํ-A, uma vez que, invocando como objetivo o desenvolvimento sustentável, tema ainda aberto na literatura, positiva princípios nos seis incisos de seu parágrafo único. O que a lei chama de princípios, todavia, nada mais são que "uma linha de ação a ser adotada pela administração e alguns, claramente, incoerentes" (ANTUNES, 2014, p. 49).

Uma das Ações Diretas de Inconstitucionalidade (ADIs), ajuizada em 13 de janeiro de 2013, partiu da Procuradoria Geral da República, que, fundamentada nos artigos 102, I, a, p e 103, VI da CRFB/88, pleiteou abertura do controle abstrato de constitucionalidade, buscando a declaração pelo STF da inconstitucionalidade de dispositivos da Lei n. 12.651/12, que não se coadunariam com os artigos 5o, 186, I e II e 225, da $\mathrm{CRFB} / 88$, exatamente por diminuírem o padrão de proteção ambiental e, mais, ainda, extinguirem espaços territoriais especialmente protegidos. Posteriormente, em 4 de abril de 2013, o Partido Socialismo e Liberdade (Psol) ajuizou, com a mesma finalidade, a ADI o 4.937.

Para fins de delimitação do objeto de pesquisa, entretanto, neste estudo optou-se por analisar o retrocesso socioambiental e a decisão do STF quanto, especificamente, à área rural consolidada, bem como à anistia de multas, à isenção de desmatamentos irregulares, à imunidade à fiscalização e à consolidação dos danos ambientais, uma vez que todos os dispositivos inserem como marco legitimatório a data de 22 de julho de 2008, inexistindo pertinência jurídica concebível, ferindo o amplo espectro de proteção ambiental garantido pela CRFB/88. Sabe-se que, para explicitar o marco temporal, "levou-se em consideração a publicação do Decreto no 6.514, de 22 de julho de 2008", mas sem dúvida, trata-se de "Polêmica escolha do legislador, que acabou por gerar verdadeira anistia a proprietários e possuidores de imóveis rurais irregulares" (LEHFELD; CARVALHO; BALBIM, 2013, p. 160), o que se passa a demonstrar.

\subsection{A Área Rural Consolidada (Artigo 3ํ, IV e Artigo 7ㅇ, §3으)}

São consideradas áreas rurais consolidadas as de imóveis rurais com ocupação humana preexistente a 22 de julho de 2008, com a presença de edificações, benfeitorias ou atividades agrossilvipastoris, ressaltando-se que, neste último caso, é admitida a adoção de regime de pousio (BRASIL, 2012). Ou seja, é aquela que, ocupada pelo homem, tenha benfeitorias por ele realizadas, nas quais, mesmo que haja supressão de vegetação, modificação de solo ou quaisquer tipos de impacto ou danos ambientais, todo o prejuízo ambiental ocorrido até a data de 22 de julho de 2008 é considerado pela lei materializado e, por isso mesmo, não será sequer estimado.

Além da mesma impertinência do marco temporal, o Código Florestal, em seu artigo 70, estabelece proteção às vegetações situadas em Áreas de Preservação Permanentes (APPs), que são uma "área protegida, coberta ou não por vegetação nativa, com a função ambiental de preservar os recursos hídricos, a paisagem, a estabilidade geológica e a biodiversidade, facilitar o fluxo gênico de fauna e flora, proteger o solo e assegurar o bem-estar das populações humanas" (BRASIL, 2012). Nesse sentido, é imposta ao proprietário, possuidor ou ocupante a qualquer título a obrigação de manter intacta e protegida referida área (BRASIL, 2012).

$\mathrm{Na}$ contramão do que se espera de uma legislação protetiva, no entanto, o § 3ㅇ, aqui questionado, permite amplamente concessões de novas autorizações para supressão de vegetação àqueles que procederam contra legem até 22 de julho de 2008, mesmo que tenham degradado a vegetação local e desprotegido a APP. Permissividade escancarada mediante a própria interpretação do artigo, que, em seu caput, é expresso ao declarar que "A vegetação situada em Área de Preservação Permanente deverá ser mantida pelo proprietá- 
rio da área, possuidor ou ocupante a qualquer título, pessoa física ou jurídica, de direito público ou privado" (BRASIL, 2012) e, nesse contexto, "A expressão 'deverá' não comporta discricionariedade ou dilações interpretativas" (LUCIANO; LUCIANO, 2015, p. 33), razão pela qual não é possível compreender o parâmetro de diferenciação temporal. Nessa perspectiva:

Não há fundamento jurídico razoável para a fixação do dia 22 de julho de 2008 como o limite para a regularização dessas ocupações. Seria mais plausível, pelo bem jurídico tutelado pelo Código Florestal, a data, por exemplo, de edição do primeiro regulamento da Lei de Crimes Ambientais, qual seja, o Decreto no 3.179 , de 21 de setembro de 1999. O fato é que, com a ampla regularização dada pelo texto final do diploma sob análise, favorece-se a não recuperação de extenso passivo ambiental existente no país (LEHFELD; CARVALHO; BALBIM, 2013, p. 36).

A permissão para novos desmatamentos, sem recuperação prévia daqueles já realizados de maneira irregular, isenta agentes causadores de danos ambientais, elidindo a obrigação de reparação do dano, sem fundamentação juridicamente concebível. As ADIs em análise suscitaram, pois, ofensa ao artigo 225, parágrafos 1 으, 3ㅇ e 4으, ao artigo 186 da CRFB/88, além do princípio da isonomia, uma vez que o impedimento a novas autorizações deveria atingir a todos indistintamente. $O$ critério deve ser a subsistência de dano sem a reparação na forma da lei.

\subsection{Isenção de Desmatamentos Irregulares (Artigo 17, §3으)}

Assim como a APP, a Reserva Legal (RL) é dotada de proteção no Código Florestal, sendo imposto o dever de conservá-la nos mesmos moldes da área de preservação (BRASIL, 2012). Para tanto, considera-se RL a

área localizada no interior de uma propriedade ou posse rural, delimitada nos termos do art. 12 , com a função de assegurar o uso econômico de modo sustentável dos recursos naturais do imóvel rural, auxiliar a conservação e a reabilitação dos processos ecológicos e promover a conservação da biodiversidade, bem como o abrigo e a proteção de fauna silvestre e da flora nativa (BRASIL, 2012).

A expectativa de proteção é tanta que as Áreas de Preservação Permanente e as Reservas Legais, juntamente com as Unidades de Conservação, são denominadas de espaços territoriais protegidos, formando o que também se denomina de mosaico de espaços protegidos, quando, conforme a Lei n. 9.985/2000, artigo 26, "existir um conjunto de unidades de conservação de categorias diferentes ou não, próximas, justapostas ou sobrepostas, e outras áreas protegidas públicas ou privadas" (BRASIL, 2000).

Nessas circunstâncias, vale mencionar que o próprio Código Florestal determina que as funções ecossistêmicas da APP e da RL são diversas (BRASIL, 2012), mas ambas são parte da ressignificação do direito de propriedade que possui função social e ambiental como um dever jurídico (COSTA; RESENDE, 2011).

O artigo 17, então, impõe a conservação e seu $\S 3$ o determina a imediata suspensão das atividades realizadas em RL desmatada de maneira irregular, mas, logo após garantir a proteção, simplesmente, no mesmo dispositivo, isenta os desmatamentos irregulares ocorridos antes de 22 de julho de 2008.

Nesse sentido, além de se permitir a continuidade da exploração de atividade econômica, ilicitamente instalada e desenvolvida, privilegia o degradador que, dentro do marco temporal eleito infundadamente pela lei, fica livre do dever de reparar o dano ambiental. Além disso, "É desnecessário o referido parágrafo, pois evidentemente que as atividades irregulares, como regra, devem ser suspensas imediatamente" (LEHFELD; CARVALHO; BALBIM, 2013, p. 160).

Sob esses fundamentos, as ADIs questionam a ofensa ao dever geral de proteção do artigo 225 da CRFB/88, além da exigência de reparação do dano ambiental (artigo 225, §3으), restauração dos processos eco-

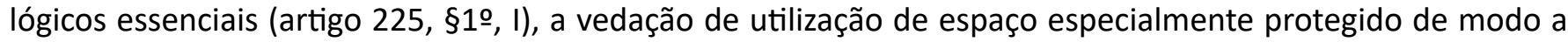
comprometer os atributos que justifiquem sua proteção (artigo 225, §1ํ, III), claro retrocesso socioambiental.

\subsection{Imunidade à Fiscalização e Anistia de Multas (Artigo 59, §§ 4으 e 5으)}

Além da área rural consolidada e da isenção dos desmatamentos irregulares anteriormente abordados, o Código Florestal dedicou um capítulo específico para as Disposições Transitórias e, nesse viés, estabeleceu que União, Estados e Distrito Federal deverão, no prazo de 1 (um) ano da publicação da lei, por ato do chefe 
do Executivo, instituir Programas de Regularização Ambiental (PRAs), cujo objetivo é a adequação e recuperação das Áreas de Preservação Permanente e de Reserva Legal dos imóveis rurais tidos como irregulares dentro da previsão do NCF (BRASIL, 2012).

Para tanto, ainda que aparente ser mais protetivo um programa de recuperação de passivos ambientais, o §4ำ coloca em risco a materialização da proteção e preservação ao impor que:

No período entre a publicação desta Lei e a implantação do PRA em cada Estado e no Distrito Federal, bem como após a adesão do interessado ao PRA e enquanto estiver sendo cumprido o termo de compromisso, o proprietário ou possuidor não poderá ser autuado por infrações cometidas antes de 22 de julho de 2008, relativas à supressão irregular de vegetação em Áreas de Preservação Permanente, de Reserva Legal e de uso restrito (BRASIL, 2012).

Isso porque, na hora de operacionalizar, ou seja, simplesmente na aplicabilidade prática, "o §4a estabelece uma anistia administrativa para as infrações que, eventualmente, tenham sido praticadas em desfavor da proteção das florestas e demais formas de vegetação. De fato, como se sabe, as multas administrativas prescrevem no prazo de cinco anos" (ANTUNES, 2014, p. 294). Não obstante, é questionável a inexistência de requisitos mínimos, parâmetros objetivos que indiquem a criação e condução dos PRAs.

Para completar, o § 5o perdoa multas já arbitradas aos que aderirem ao PRA e cumprirem suas cláusulas, o que, mais uma vez, premia aqueles que descumpriram as normas então vigentes, reduzindo a proteção ambiental. Em resumo, dispensa-os da obrigação de recuperação integral dos danos ambientais e do pagamento de multa (BRASIL, 2012). "Por isso mesmo, o §5ㅇ, com essa possibilidade ampla de prorrogação das sanções parece sem finalidade" (ANTUNES, 2014, p. 295).

Ora, o Novo Código Florestal foi publicado aos 28 de maio de 2012; considerando-se que foi concedido prazo de um ano, prorrogável por mais um para a edição das normas relativas ao PRA, assim, a exigência pode ser estendida até, no mínimo, 28 de maio de 2014, sendo certo que o dies a quo é 22 de julho de 2008, ou seja, cerca de seis anos antes da plena exigibilidade do PRA; logo, no meu ponto de vista, foi concedida ampla anistia administrativa, através da adoção de um mecanismo diversionista (ANTUNES, 2014, p. 295).

Por essas razões, as ADIs atacam a ofensa ao sistema de controle ambiental, violando o artigo 225 , § 3 o da CRFB/88, que expressa, claramente, que "as condutas e atividades consideradas lesivas ao meio ambiente sujeitarão os infratores, pessoas físicas e jurídicas, a sanções penais e administrativas, independentemente da obrigação de reparar os danos causados" (BRASIL, 1988). E as vulnerabilidades ainda são verificadas em outros dispositivos, sobretudo quando, além de isenções, imunidades e anistias, permite-se consolidar danos ambientais já experimentados, conforme se passa a explicar.

\subsection{A Consolidação de Danos Ambientais (Artigos 61-A, 61-B, 61-C, 63)}

A alteração mais impactante é a que permite a consolidação de danos ambientais decorrentes de infrações à legislação de proteção às APPs, praticados até 22 de julho de 2008, nas mais variadas formas, conforme artigos 61-A, 61-B, 61-C e 63, ou seja, o proprietário rural que agiu em desconformidade com a lei anteriormente vigente e que tenha causado danos, não será obrigado a repará-los integralmente (BRASIL, 2012).

Os dispositivos mencionados listam como critério para escolha de áreas que devem ou não ser recuperadas apenas o tamanho das propriedades, sem qualquer vinculação com bioma, espécies de fauna e flora ou processos ecológicos essenciais. Deixa o legislador a dúvida quanto ao critério técnico de escolha, possibilitando, inclusive, espaço para fraudes e simulações em negócios jurídicos para modificação de área rural para elisão quanto ao dano e seu ressarcimento.

O artigo 61-A, que possui 17 incisos, regulamenta atividades já praticadas nas APPs e que já mostravam ofensa às normas existentes e, ainda, permitiu a continuidade de atividades agrossilvipastoris, de ecoturismo e de turismo rural nas áreas consolidadas até 22 de julho de 2008 (BRASIL, 2012). Nessa perspectiva, emerge o pensamento de que, como afirma Antunes (2014, p. 305), a intenção seria legitimar as atividades ofensivas à norma vigente, mas, além disso, "não se justifica que algumas tenham sido admitidas como autorizáveis e outras não; até mesmo porque não foram apresentadas justificativas razoáveis para autorização" (ANTUNES, 2014, p. 305). 
Mais, ainda, o §9ㅇ do artigo 61-A abre a possibilidade para outras formas de exceção às regras gerais de observância das APPs, o que é contraditório ao próprio NCF, que estabelece primeiro um critério taxativo de exceções e depois amplia com um requisito simples de comunicação ao Cadastro Ambiental Rural (CAR) (BRASIL, 2012). Antunes (2014) argumenta que esse artigo traz critérios que não são ambientais, porquanto delimitação dimensional de posse e propriedades não garantem respeito ao equilíbrio ecológico, sequer se sabe se há relação de causa e efeito aferível. Dessa forma, os interesses só poderiam ser outros, uma vez que "Foram utilizados critérios de natureza 'social' que expressam reconhecimento por parte da administração e do 'legislador', vez que introduzidos pela via da Medida Provisória, da chamada 'força normativa dos fatos', ou uma 'situação consolidada pelo tempo'"' (ANTUNES, 2014, p. 308-309).

Vale mencionar que a força normativa dos fatos é terreno fértil para ativismo judicial, pois,

na tarefa de concretização da Constituição, o Supremo Tribunal Federal aplica-se a prover a sua força normativa e sua função estabilizadora, reportando-se à integridade da ordem concreta da qual ela é a representação mais elevada no plano do Direito posto. A sua mais prudente aplicação, nas situações de exceção, pode corresponder exatamente à desaplicação de suas normas a essas situações (VIEIRA; BRASIL, 2007, p. 315).

Do mesmo modo, sob esses fundamentos, as ADIs questionam a ofensa ao dever geral de proteção do artigo 225 da CRFB/88, além da exigência de reparação do dano ambiental (artigo 225, § 3)), restauração dos processos ecológicos essenciais (artigo $225, \S 1$ 이 I), a vedação de utilização de espaço especialmente protegido de modo a comprometer os atributos que justifiquem sua proteção (artigo 225 , §1으, III), claro retrocesso socioambiental.

Encerrada, portanto, a resumida e pontual síntese dos dispositivos aqui estudados e das causas que ensejaram as ADIs, passa-se a demonstrar a decisão do STF e, posteriormente, a rediscussão de seus fundamentos, conforme normas e preceitos constitucionais vigentes.

\section{A DISCUTíVEL DECISÃO DO STF E A DESPROTEÇÃO DO MEIO AMBIENTE}

As ADIs propostas em 2013 arrastaram-se no Supremo Tribunal Federal para julgamento por exatos 5 (cinco) anos, tramitação marcada por pedidos de admissões de amicus curiae, pedidos de vista e suspensões.

Para compreender conceitos, termos e consequências externas ao Direito, o STF promoveu Audiência Pública que, segundo o próprio ministro relator Luiz Fux, "se realiza basicamente quando o Supremo Tribunal Federal é instado a solucionar questões de cunho interdisciplinar. Essa questão relativa ao Código Florestal transcende à mera questão jurídica" (BRASIL, 2016). Na oportunidade foram ouvidos 23 expositores, ${ }^{1}$ de diversas áreas de interesse, os quais, pelo regimento interno do STF, tiveram apenas 10 minutos para se manifestarem sobre as questões técnicas do ponto de vista de sua área de afinidade, tempo insuficiente para a profundidade de abordagem e especificidades do assunto.

Enfim, em 28 de fevereiro de 2018, após julgamento do Tribunal Pleno, o STF julgou procedente em parte as ADIs para, especificamente, quanto aos dispositivos tratados neste trabalho:

\footnotetext{
${ }^{1}$ Foram os expositores: Jean Paul Metzger (Professor da Universidade de São Paulo); Rodrigo Justus de Brito (Assessor Técnico Sênior da CNA); Gerd Sparovek (Coordenador do Laboratório de Geoprocessamento, Labgeo); Annelise Vendramini (Centro de Estudos em Sustentabilidade da Escola de Administração da Fundação Getulio Vargas - FGVCES); Edís Milaré; Marcelo Cabral Santos (Secretaria de Política Agrícola do Ministério da Agricultura, Pecuária e Abastecimento); José Luiz de Attayde (Pesquisador da Associação Brasileira de Limnologia Ablimno); Ministro José Aldo Rebelo Figueiredo (Ministério da Defesa); Almerita Francisca da Silva; Sebastião Renato Valverde (Associação Brasileira de Companhias de Energia Elétrica - ABCE); Hélvio Neves Guerra (Agência Nacional de Energia Elétrica - Aneel); Nurit Bensusan (Professora Doutora da Universidade de Brasília e Pesquisadora do Instituto Socioambiental); Sergius Gandolfi (Escola Superior de Agricultura "Luiz de Queiroz" - Esalq - USP); Evaristo Eduardo de Miranda (Empresa Brasileira de Pesquisa Agropecuária, Chefe-Geral da Embrapa Monitoramento por Satélite); Sâmia Serra Nunes (Imazon); Sarney Filho (Deputado Federal - Frente Parlamentar Ambientalista); Roberto Rodrigues (Centro de Estudos do Agronegócio da Escola de Economia de São Paulo da Fundação Getulio Vargas - EESP/FGV); Raimundo Deusdará Filho (Diretor-Geral do Serviço Florestal Brasileiro - FSB); Luiz Henrique Gomes de Moura; Paulo José Prudente de Fontes (Instituto Brasileiro do Meio Ambiente e dos Recursos Naturais Renováveis - Ibama, Diretoria de Uso Sustentável da Biodiversidade e Florestas); Devanir Garcia dos Santos (Agência Nacional de Águas - ANA); Antônio Donato Nobre (Instituto Nacional de Pesquisas da Amazônia); Roberto Varjabedian (Associação Brasileira dos Membros do Ministério Público de Meio Ambiente - Abrampa). Transcrição da audiência disponível em: <http://www.stf.jus.br/arquivo/cms/audienciasPublicas/anexo/TranscriesNovoCdigoFlorestal.pdf>.
} 
[...] ii) [...] reconhecer a constitucionalidade do art. 17, § 3ㅇ, do Código Florestal; iii) por maioria, deu interpretação conforme a Constituição ao art. 59, §4, do Código Florestal, de modo a afastar, no decurso da execução dos termos de compromissos subscritos nos programas de regularização ambiental, o risco de decadência ou prescrição, seja dos ilícitos ambientais praticados antes de 22.7.2008, seja das sanções deles decorrentes, aplicando-se extensivamente o disposto no $\S 1$ o do art. 60 da Lei 12.651/2012, segundo o qual 'a prescrição ficará interrompida durante o período de suspensão da pretensão punitiva', [...]; iv) por maioria, deu interpretação conforme a Constituição ao art. 59, §5ㅇ, do Código Florestal, de modo a afastar, no decurso da execução dos termos de compromissos subscritos nos programas de regularização ambiental, o risco de decadência ou prescrição, seja dos ilícitos ambientais praticados antes de 22.7.2008, seja das sanções deles decorrentes, aplicando-se extensivamente o disposto no $\$ 1$ o do art. 60 da Lei 12.651/2012, segundo o qual 'a prescrição ficará interrompida durante o período de suspensão da pretensão punitiva', [...] vi) [...]

reconhecer a constitucionalidade do art. 61-A do Código Florestal; vii) [...] reconhecer a constitucionalidade do art. 61-B do Código Florestal; viii) [...] reconhecer a constitucionalidade do art. 61- C do Código Florestal; ix) [...] reconhecer a constitucionalidade do art. 63 do Código Florestal; [...] (BRASIL, 2018, grifo nosso).

Assim, mesmo após a oitiva de especialistas ambientalistas, cientes do direito fundamental ao meio ambiente ecologicamente equilibrado como direito de todos,

Em prol de uma ânsia produtivista socialmente excludente, observa-se que a natureza foi cooptada pelo crescimento econômico, sem se considerar a interdependência dos demais aspectos sociais, culturais, ambientais, dentre outros que formam o tecido complexo de uma localidade (SILVA; EL-DEIR; SILVA, 2017, p. 218).

Uma vez contextualizados legislação, as ADIs e a decisão do STF, passa-se à discussão dos fundamentos que encaminham por considerar ainda questionável a decisão da Corte.

\section{A PROTEÇÃO JURÍDICA DO MEIO AMBIENTE: Aspectos Conceituais e Natureza Jurídica}

Em primeiro lugar é necessário compreender o direito ao ambiente equilibrado como um direito fundamental de terceira dimensão. Nessa perspectiva:

Os direitos fundamentais de terceira dimensão, também denominados direitos de fraternidade ou de solidariedade, trazem como nota distintiva o fato de se desprenderem, em princípio, da figura do homem indivíduo como seu titular, destinando-se à proteção de grupos humanos (família, povo, nação), caracterizando-se, consequentemente, como direitos de titularidade coletiva ou difusa (SARLET, 2001, p. 52).

Embora ainda haja na literatura autores que diferenciem gerações e dimensões de direitos fundamentais, torna-se desnecessária essa fragmentação, posto que sua interpretação deve ser conjunta sem que um núcleo seja mais relevante que outro. Nesse sentido, facilmente, "Entende-se [...] superadas as infindáveis discussões sobre as gerações de direitos, [...], sem delimitar um núcleo de direitos fundamentais mais importante que outros. Se assim fosse, estaria, novamente, usando de uma interpretação axiológica que neste diapasão não é possível" (COSTA, 2016, p. 20).

Dessa compreensão extrai-se o primeiro ponto que torna questionável a decisão do STF: o reconhecimento claro da natureza jurídica da proteção ambiental como direito fundamental, por si só, evidencia uma crítica quanto ao intervencionismo do Estado, posto que não se deve inflacionar direitos fundamentais, sequer reduzi-los. Ou seja, justamente essa criação exagerada de direitos do homem cada vez mais específicos, na qual já se tem a ampla proteção, é um alerta que precisa ser observado. Desse modo, nessa onda de excesso de edição de leis, da qual o Código Florestal parece fazer parte, prevalece o cenário social de mudança de valores, em que o homem fica em segundo plano, pois a economia estaria sempre em primeiro lugar (COSTA, 2016). Disso abstrai-se que direito fundamental não deve ser objeto de indiscriminada atividade legiferante e se o for, caberia justamente ao STF o devido controle em prol de resguardo à CRFB/88, o que não foi o entendimento na decisão. 
Costa (2016) ainda afirma que é justamente a atuação do Estado que faz a concretização do direito fundamental, ora por uma atuação, ora por uma abstenção. Nesse viés, "Considerando-se que a atividade humana quase sempre implicará a alteração das condições naturais, o foco do 'Estado Ambiental' estaria nos critérios de definição para melhores condições ambientais" (ARAÚJO, 2017, p. 257).

"Desde então, tendo sido o meio ambiente consagrado como direito humano, podemos opor à regressão do Direito Ambiental argumentos jurídicos fortes, em nome da efetividade e da intangibilidade dos direitos humanos" (PRIEUR, 2012, p. 15).

Além disso, embora consagrada no texto constitucional em 1988, no artigo 225 da CRFB/88, "a ecologização da Constituição não é cria tardia de um lento e gradual amadurecimento do Direito Ambiental [...] ao contrário, o meio ambiente ingressa no universo constitucional em pleno período de formação do Direito Ambiental" (BENJAMIN, 2011, p. 84 ). Certo é, pois, que o artigo 225 indica que há, no texto constitucional, "direitos, deveres e princípios ambientais (a) explícitos e implícitos, (b) substantivos e procedimentais, e (c) genéricos e específicos" (2011, p. 114).

Isso implica uma considerável intangibilização do direito fundamental ambiental, porquanto a função de se preservar o meio ecologicamente equilibrado para as presentes e futuras gerações é ônus para antecipação de previsibilidade de danos e extrema atividade protetiva. Cabe aqui, inclusive, mencionar que a proteção esperada tem fundamento antropocêntrico, porquanto se compreende que o pacto intergeracional abstraído do artigo 225 impõe ao legislador e a todos um plus para fortalecer o amparo ao próprio ser humano.

Nesse sentido, fato é que

a Constituição não pode abdicar da salvaguarda de sua própria identidade, assim como da preservação e promoção de valores e direitos fundamentais; mas não deve ter a pretensão de suprimir a deliberação majoritária legítima dos órgãos de representação popular, juridicizando além da conta o espaço próprio da política. $O$ juiz constitucional não deve ser prisioneiro do passado, mas militante do presente e passageiro do futuro (BARROSO, 2009, p. 168).

E se a Constituição não pode, não é possível admitir, mais ainda, o atropelo de seu próprio guardião. Isso porque essa constitucionalização do Direito Ambiental traz consigo, ainda, um arcabouço principiológico que estrutura toda sua proteção, e que também indica fragilidades na decisão ora analisada, conforme se mostra a seguir.

\section{OS PRINCÍPIOS CONSTITUCIONAIS AMBIENTAIS: Teorias Sobre Princípios e Regras, o Desenvolvimento Sustentável e o Retrocesso Socioambiental}

Segundo Sampaio, Wold e Nardy (2003, p. 45), "princípios são enunciados deotônticos que sedimentam e cristalizam valores e políticas no ordenamento jurídico (princípios formais e materiais", além de "normas técnico-operacionais do sistema jurídico que orientam mais diretamente as operações estruturais sistêmicas (princípios funcionais ou operacionais)".

Princípios e regras são espécies do gênero norma, destacando-se que "os princípios de Direito Ambiental têm a ossatura dos demais princípios; como eles, gozam das peculiaridades de sua dinâmica e relativa abertura semântica" (SAMPAIO; WOLD; NARDY, 2003, p. 47).

Aqui se encontra outro ponto de discordância com a decisão do STF em comento: a aplicabilidade das teorias sobre princípios e regras que hierarquizam valores, ou seja, puro e simples decisionismo.

Para Alexy (2014), princípios possuem alto grau de generalidade, compondo-se em mandados de otimização, enquanto as regras possuem baixo grau de generalidade, cabendo-lhes serem cumpridas ou não, descumprimento considerado no campo da validade da regra. Nesse sentido, havendo conflito de regras, o ideal para ele é que se tenha uma cláusula de exceção que elimine o conflito ou que se declare inválida pelo menos uma das regras. Já para colisões de princípios, o autor sugere uma hierarquização dos valores do caso concreto para que um princípio possa ceder ao outro, ou seja, em cada caso, diferentes pesos para valores. 
Contrário a Alexy, Dworkin (2014) afirma que as regras estão para o "tudo ou nada", visando a uma aplicação disjuntiva; e os princípios, para a justiça ou imparcialidade, ou outra dimensão da moralidade, devem direcionar a coerência da decisão, ou seja, ao invés de colisão, há somente concorrência, sem hierarquização de valores.

Assim sendo, pode-se afirmar que "Dworkin não entende os princípios como dimensão de 'peso', mas como um critério de prevalência do bom senso. Portanto, não existe colisão de princípios, como preceituado por Alexy, mas sim uma concorrência que deve ser dosada" (COSTA, 2016, p. 35).

A crítica, pois, que desse ponto se pode tecer à decisão do STF é justamente ter se colocado uma escala de valores no qual o interesse econômico prevalece sobre a proteção ao meio ambiente, sob argumentos de convicções nada jurídicas. A análise alexyana do STF fomenta tão somente a insegurança jurídica, pois desconsidera absolutamente que "tanto o direito a um ambiente ecologicamente equilibrado quanto o direito a um desenvolvimento econômico devem andar juntos para que não haja sobreposições de valores" (COSTA, 2016, p. 36).

Mais, ainda, "Depois, é preciso compreender que o conflito entre princípios advoga solução jurídica, de adequação es seleção em função do caso concreto, nunca por um juízo de preferência segundo critérios de ponderação que, a pretexto de objetividade, descamba para decisionismo" (SAMPAIO; WOLD; NARDY, 2003, p. 46).

A decisão do STF é tão contraditória que a simples invocação do princípio basilar do Direito Ambiental encaminha a interpretação da concorrência e aplicabilidade do bom senso, tal qual preceitua Dworkin com conceitos deontológicos.

Nessa perspectiva, o princípio do desenvolvimento sustentável é o basilar para a proteção ambiental brasileira, matriz de outros princípios nos quais se encontra implicitamente contido, sendo reconhecido pela CRFB/88 mesmo sem menção expressa, no artigo 225 , que resume em sua redação o projeto sustentável de uso da natureza.

Sampaio, Wold e Nardy (2003) demonstra que até mesmo a previsão de coexistência entre a livre- iniciativa e a defesa do meio ambiente, como meio de garantia de vida digna, considera a designação do desenvolvimento sustentável, conforme os ditames de justiça social e

ao inserir no conceito de função social da propriedade rural o aproveitamento racional e adequado; a utilização adequada dos recursos naturais disponíveis e preservação do meio ambiente; a observância das disposições que regulam as relações de trabalho; e a exploração que favoreça o bem-estar dos proprietários e dos trabalhadores (SAMPAIO; WOLD; NARDY, 2003, p. 51).

"Por isso, parece ser necessário mover-se na estrutura da linguagem dos direitos; levar os direitos a sério" (MARCO; MEZZAROBA, 2017, p. 342), ponto especificamente questionável na decisão em comento, frise-se, quanto aos dispositivos anteriormente trabalhados.

São diversos os princípios constitucionais ambientais que até a contemporaneidade servem de instrumentos protetivos e, como dito, todos de mesmo valor hierárquico. Assim, contudo, como o desenvolvimento sustentável, há um princípio que é implícito nos demais, uma vez que sua violação, por si só, demonstra supressão de proteção. Nessa dimensão, questiona-se também o retrocesso real materializado pela decisão do STF, sendo o princípio ofendido "decorrente do sistema jurídico-constitucional, entende que se uma lei, ao regulamentar um mandamento constitucional, instituir determinado direito, ele se incorpora ao patrimônio jurídico da cidadania e não pode ser arbitrariamente suprimido" (LIMA; FERREIRA, 2018, p. 370).

Pode-se afirmar, então, segundo Prieur (2012), que a vedação ao retrocesso configura função integrativa, uma vez que o respeito ao não retrocesso implica, necessariamente, além deste princípio, um respeito absoluto àqueles já reconhecidos como princípios ambientais. "As bases dessa argumentação jurídica repousam sobre três elementos: a própria finalidade do Direito Ambiental, a necessidade de se afastar o princípio de mutabilidade do direito e a intangibilidade dos direitos humanos" (PRIEUR, 2012, p. 16).

Não obstante, o Direito Ambiental sujeita-se a diversos fatores indicativos de recuo, que precisam ser considerados na atividade legislativa, mas, mais ainda, em sua interpretação e aplicação: 
a) ameaças políticas: a vontade demagógica de simplificar o direito leva à desregulamentação e, mesmo, à "deslegislação" em matéria ambiental, visto o número crescente de normas jurídicas ambientais, tanto no plano internacional quanto no plano nacional; b) ameaças econômicas: a crise econômica mundial favorece os discursos que reclamam menos obrigações jurídicas no âmbito do meio ambiente, sendo que, dentre eles, alguns consideram que essas obrigações seriam um freio ao desenvolvimento e à luta contra a pobreza; c) ameaças psicológicas: a amplitude das normas em matéria ambiental constitui um conjunto complexo, dificilmente acessível aos não especialistas, o que favorece o discurso em favor de uma redução das obrigações do Direito Ambiental (PRIEUR, 2012, p. 12).

Daí, pode-se fazer a construção de que, como mencionado alhures, sendo um direito humano e fundamental, está-se diante de intangibilidade desse direito, por isso a crítica à ampla atividade legiferante e à falta de controle dela pelo STF, o que é claro retrocesso. "Na realidade, a não regressão dos direitos humanos é mais que implícita, ela é ética, prática e quase judiciária" (PRIEUR, 2012, p. 18).

Seguindo os questionamentos em relação à decisão em que se absteve do controle de constitucionalidade necessário, verifica-se que a mera falta de cuidado com a edição de uma legislação que reflete em vários pontos da sociedade já se torna duvidosa. Segundo Antunes (2014, p. 9), "não houve um pré-projeto elaborado por uma comissão de técnicos e juristas que pudesse servir de base para as discussões congressuais e, assim, partindo do estado do conhecimento jurídico e técnico sobre a matéria", pudesse-se editar legislação eficaz, eficiente e, de fato, protetiva.

O sujeito de direitos tem cada vez mais ampliado o espectro de proteção à dignidade da pessoa humana, com vistas a efetivar seu patrimônio político-jurídico que vem se consolidando em intenso caminho histórico, justamente, "para aquém do qual não deve retroceder" (SARLET; FENSTERSEIFER, 2013, p. 287).

Outro ponto de tensão visto na decisão do STF, entendido como o mais discutível, quanto à área rural consolidada, bem como à anistia de multas, à isenção de desmatamentos irregulares, à imunidade à fiscalização e à consolidação dos danos ambientais, todos os dispositivos tendo marco legitimatório a data de 22 de julho de 2008, é a aparente desconsideração da sociedade de risco, que se revela pela "interdependência sistêmica dos atores da modernização da economia e a consequente ausência de causas específicas e responsabilidades determináveis" (THOMÉ, 2014, p. 21), ou seja, os riscos na sociedade moderna não são evidentes, não são aparentes. São "Irreais na medida em que seus efeitos são imperceptíveis no momento de análise, e reais tendo em vista suas inevitáveis consequências sobre o meio ambiente e saúde humana, verificáveis com o decurso do tempo" (THOMÉ, 2014, p. 21). Desconsiderou o STF, inclusive, as exposições trazidas na Audiência Pública, ${ }^{2}$ oportunidade em que o Senhor Sergius Gandolfi, representante da Escola Superior de Agricultura "Luiz Queiroz" - Esalq - USP) suscitou que:

A Lei no 12.651, o que ela faz? Transforma em parcialíssima a reparação que anteriormente já era parcial, e o pior, ela eterniza o dano local nas áreas consolidadas. Ela eterniza o dano à distância e ela gera consequências ambientais, sociais e econômicas. E pior que isso, Ministro, pra gente chegar já próximo do final. [...] Torna legal os lucros indevidos pregressos e futuros em áreas que a Constituição protege (BRASIL, 2016)

Outro expositor, senhor José Luiz de Attayde, pesquisador da Associação Brasileira de Limnologia Ablimno -, foi categórico:

O conhecimento acumulado nas décadas de 70 e 80, desde os estudos pioneiros da década de 60, que removeram a vegetação em bacias experimentais para avaliar o impacto da remoção da vegetação nos recursos hídricos, já mostrava a necessidade de ampliar de cinco metros para trinta metros a faixa marginal de APPs, para uma efetiva conservação das funções ecológicas das matas ciliares. Contudo, a Lei 12.651, de 25.5.2012, também chamada de Lei de Proteção da Vegetação Nativa, permite a consolidação dos danos ambientais em áreas de preservação permanente decorrentes de infrações legais praticadas até 22 de julho de 2008. [...] Essa alteração ocasiona grande impacto em rios de planícies, que inundam sazonalmente vastas áreas marginais de várzeas, podendo reduzir, até pela metade, a área de vegetação nativa a ser protegida (BRASIL, 2016).

\footnotetext{
2 Transcrição da audiência. Disponível em: <http://www.stf.jus.br/arquivo/cms/audienciasPublicas/anexo/TranscriesNovoCdigoFlorestal. pdf>. Acesso em: 22 abr. 2018.
} 
Nesse sentido, conforme Prieur (2012, p. 18), “O retrocesso em matéria ambiental não é imaginável. Não se pode considerar uma lei que revogue normas antipoluição ou normas sobre a proteção da natureza, ou, ainda, que suprima, sem justificativa, áreas ambientalmente protegidas".

Não se pretende que a vedação ao retrocesso obste o progresso, mais precisamente, no caso deste estudo, o mito do desenvolvimento econômico e supostamente sustentável. Tratando-se, todavia, de direito fundamental, as alterações à proteção ao meio ambiente são restritas, ou seja, podem ser realizadas, mas dentro dos limites da proporcionalidade e razoabilidade, posto que, nessa interpretação, a interferência legislativa deve ser mínima, assim como não pode estabelecer uma proteção ineficaz ou ineficiente, pois deve-se preservar o núcleo existencial do direito fundamental, indivisível e correlato à dignidade da pessoa humana. A proteção ambiental é, ainda, afirmação de outros direitos fundamentais, tais como vida digna, moradia, saúde, saneamento básico, trabalho e outro direitos sociais (SARLET; FENSTERSEIFER, 2012). Dessa forma, Sarlet e Fensterseifer (2012) explicam que qualquer diminuição de níveis de proteção de direitos socioambientais é suspeita e deverá ser submetida ao controle de constitucionalidade.

O retrocesso já é vislumbrado pela mera inércia, pois "aguardar que os riscos se transformem em perigos perceptíveis e agudos para que sejam tomadas providências efetivas pode significar mudanças ambientais irreversíveis para pior" (THOMÉ, 2014, p. 27), sendo perceptível:

O inegável interesse de alguns grupos em continuar a produzir ameaças, minimizando-as em suas argumentações, exatamente a partir da dificuldade natural dos seres humanos em notá-las. Tais grupos, beneficiados com a manutenção do ritmo acelerado de crescimento econômico e a utilização desmedida dos recursos naturais, geralmente tentam desqualificar os argumentos daqueles que apontam os efeitos deletérios progressivos das atividades antrópicas sobre o meio ambiente (THOMÉ, 2014, p. 27).

Por isso mesmo, o desconhecimento de riscos jamais pode ser interpretado como inexistência deles. Ao contrário, faz parte do arcabouço principiológico ambiental brasileiro, inclusive, a necessária capacidade de se antecipar aos impactos negativos sobre o meio ambiente, mesmo quando houver dúvida sobre sua ocorrência. É, pois, ofender o princípio da precaução desconsiderá-lo, postergando medidas eficazes para evitar a degradação, tal qual faz o Novo Código Florestal, legitimado pela decisão do STF. É mais que contraditório.

Nada mais demonstra o STF do que a máxima revelada por Beck (2016), porquanto, na falta de conhecimento de risco ou experimentação do dano, ninguém se sacrifica previamente - tônica da sociedade de risco -, noção de acomodação que demonstra ainda a ausência de visão coletiva quanto ao meio ambiente, estando claro que para se mudar um ethos deve haver plena consciência de visão coletiva.

Esperava-se uma importância à participação popular nas questões socioambientais, sobretudo nas tomadas de decisão, uma vez que o bem juridicamente tutelado é difuso, de interesse de toda a coletividade. Ora, "O Estado constitucional e democrático de direito, no contexto da sociedade de risco, alicerça-se sobre os princípios do desenvolvimento sustentável e da precaução e no conceito substancial de democracia" (THOMÉ, 2014, p. 85), o que implica na participação da sociedade. Desse modo,

Cumprir o princípio da proibição de retrocesso, em tal cenário, não acrescenta custos; ao revés, economiza despesas, presentes e futuras, tanto em capital financeiro mal-empregado, como em capital natural dilapidado. [...] Assim é porque, a se enfraquecer a eficácia da Constituição, pelo retrocesso na legislação infraconstitucional, cria-se para seus destinatários-beneficiários (= a coletividade) um campo insuperável e perverso de "reserva do impossível", um conjunto de normas retóricas, sem eficácia prática: impossibilidade de proteger os valores referendados na Constituição, impossibilidade de traduzir as suas ordens em ações concretas, impossibilidade de densificar, legislativa e minimamente, o seu conteúdo e expressão (BENJAMIN, 2012, p. 61).

Ou seja, caberia ao STF, em último caso, garantir "a concretude das condições de um mínimo existencial ecológico, desde uma perspectiva de efetivação dos princípios da dignidade da pessoa humana e da segurança jurídica" (MOLINARO, 2012, p. 89), o que não se verificou na decisão analisada. 


\section{CONSIDERAÇÕES FINAIS}

A decisão do Supremo Tribunal Federal nas Ações Diretas de Inconstitucionalidade (ADIs) 4.902 e 4.937,

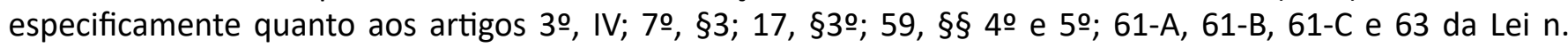
12.651/2012, Novo Código Florestal (NCF), privilegia interesses econômicos em detrimento da proteção ambiental.

Nesse sentido, questiona-se a decisão em comento exatamente por entender-se em desalinho com a proteção constitucional já alcançada, desconsiderando o dever de proteção ambiental e de promoção da sustentabilidade.

A decisão aponta em sentido contrário ao controle de constitucionalidade esperado, considerando a natureza do objeto das ações, ou seja, um direito fundamental que, por essa razão, torna-se intangível e sujeito a todo um arcabouço de protetividade e segurança jurídica.

Como consequência à natureza de um direito fundamental a um meio ambiente ecologicamente equilibrado, evidencia-se a primeira crítica - quanto ao intervencionismo do Estado - que, em atividade legiferante desmedida, inflaciona direitos fundamentais ou os reduz, questão absolutamente incompatível com um Estado socioambiental de Direito.

Não obstante, a constitucionalização do Direito Ambiental implica em um arcabouço principiológico que não deve ser valorado por meio de hierarquização. Nesse viés, não há direito fundamental, valores ou princípios hierarquicamente superiores a outros, razão pela qual a decisão, ao privilegiar interesses econômicos em detrimento do meio ambiente, atropela a proteção adequada do meio ambiente e sua compatibilidade com o desenvolvimento progressivo do Estado.

Com isso, ofende-se, ainda, o próprio princípio ambiental do desenvolvimento sustentável e o princípio da vedação ao retrocesso socioambiental, pois, diante da flagrante inconstitucionalidade dos dispositivos do Código Florestal, o STF legitimou danos ambientais e anistiou o dever de reparação aos prejuízos ambientais sofridos, desconsiderando o contexto da sociedade de risco.

Desse modo, contrariamente à decisão do STF, defende-se a inconstitucionalidade dos dispositivos tratados neste estudo - artigos 3ㅇ, IV; 7ㅇ, §3; 17, §3ㅇ; 59, §§ 4으 e 5우 61-A, 61-B, 61-C e 63, todos da Lei $n$. $12.651 / 2012$-, sob o fundamento de que, além da ausência de respaldo jurídico para desconsiderar danos e áreas desprotegidas até a data de 22 de julho de 2008, há claro retrocesso ambiental na supressão das áreas protegidas e, tratando-se de direitos intangíveis, deve-se pautar por sua garantia e segurança jurídica.

\section{REFERÊNCIAS}

ALEXY, Robert. Teoria dos direitos fundamentais. 2. ed. São Paulo: Malheiros, 2014.

ANTUNES, Paulo de Bessa. Comentários ao novo Código Florestal. 2. ed. atual. São Paulo: Atlas, 2014.

ARAÚJO, Giselle Marques de. Função ambiental da propriedade: uma proposta conceitual. Revista Veredas do Direito, Belo Horizonte, v. 14, n. 28, p. 251-276, jan./abr. 2017. Disponível em: <http://www.domhelder.edu.br/revista/index.php/veredas/ article/view/985/546>. Acesso em: 22 abr. 2018.

BARROSO, Luís Roberto. Curso de direito constitucional contemporâneo: os conceitos fundamentais e a construção do novo modelo. São Paulo: Saraiva, 2009.

BECK, Ulrich. Sociedade de risco: rumo a outra modernidade. Tradução Sebastião Nascimento. 2. ed. São Paulo: Editora 34, 2016.

BENJAMIN, Antônio Herman. Direito Constitucional Ambiental Brasileiro. In: CANOTILHO, José Joaquim Gomes; LEITE, José Rubens Morato (Org.). Direito Constitucional Ambiental Brasileiro. 4. ed. rev. São Paulo: Saraiva, 2011.

. Princípio da Proibição de Retrocesso Ambiental. In: BRASIL; SENADO FEDERAL; COMISSÃO DE MEIO AMBIENTE, DEFESA DO CONSUMIDOR E FISCALIZAÇÃO E CONTROLE (CMA). Princípio da Proibição de Retrocesso Ambiental. Brasília: Senado Federal, 2012. Disponível em: <http://www2.senado.leg.br/bdsf/item/id/242559>. Acesso em: 22 abr. 2018.

BRASIL. Constituição da República Federativa do Brasil de 1988. Brasília, 5 de outubro de 1988. Disponível em: <http://www. planalto.gov.br/ccivil_03/decreto/D70235cons.htm>. Acesso em: 22 abr. 2018.

. Lei $n$ o 9.985, de 18 de julho de 2000. Regulamenta o art. 225, § 1으, incisos I, II, III e IV da Constituição Federal, institui o Sistema Nacional de Unidades de Conservação da Natureza e dá outras providências. Brasília, 2000. Disponível em: <http:// www.planalto.gov.br/ccivil_03/leis/I9985.htm>. Acesso em: 22 abr. 2018. 
. Lei $n$ o 12.651, de 24 de maio de 2012. Dispõe sobre a proteção da vegetação nativa; altera as Leis $n^{\text {os }} 6.938$, de 31 de agosto de 1981, 9.393, de 19 de dezembro de 1996, e 11.428, de 22 de dezembro de 2006; revoga as Leis $n^{\text {os }} 4.771$, de 15 de setembro de 1965, e 7.754, de 14 de abril de 1989, e a Medida Provisória n².166-67, de 24 de agosto de 2001; e dá outras providências. Brasília, 2012. Disponível em: <http://www.planalto.gov.br/ccivil_03/_ato2011-2014/2012/lei/l12651.htm>. Acesso em: 22 abr. 2018.

BRASIL. Notas taquigráficas da audiência pública nas Ações Diretas de Inconstitucionalidade no 4901, 4902,4903 e 4937. Brasília, maio 2016. Disponível em <http://www.supremo.jus.br/arquivo/cms/audienciasPublicas/anexo/TranscriesNovoCdigoFlorestal.pdf>. Acesso em: 22 abr. 2018.

. Supremo Tribunal Federal. ADI 4902. Relator: Luiz Fux. Brasília, 28 de fevereiro de 2018. Disponível em: <http://portal.

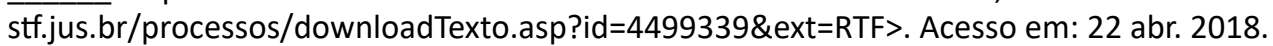

COSTA, Beatriz Souza. Meio ambiente como direito à vida: Brasil, Portugal e Espanha. 3. ed. Rio de Janeiro: Lumen Juris, 2016. COSTA, Beatriz Souza; RESENDE, Elcio Nacur. O bem sob a ótica do direito ambiental e do direito civil: uma dicotomia irreconciliável? Revista Brasileira de Políticas Públicas, Brasília, v. 1, n. 3, p. 43-70, dez./2011. Disponível em: <https://www.publicacoesacademicas.uniceub.br/RBPP/article/view/1518>. Acesso em: 22 abr. 2018.

DWORKIN, Ronald. O império do Direito. 3. ed. São Paulo: Martins Fontes, 2014.

LEHFELD, Lucas de Souza; CARVALHO, Nathan Castelo Branco de; BALBIM, Leonardo Isper Nassif. Código Florestal comentado e anotado artigo por artigo. 2. ed. rev. atual. Rio de Janeiro: Forense; São Paulo: Método, 2013.

LIMA, Fabrício Wantoil; FERREIRA, Rildo Mourão. Novo Código Florestal: desobrigação quanto à averbação da reserva legal na matrícula do imóvel. Revista Jurídica Unicuritiba, Curitiba, v. 1, n. 50, p. 343-373, 2018. Disponível em: <http://revista.unicuritiba.edu.br/index.php/RevJur/article/view/2554>. Acesso em: 22 abr. 2018.

LUCIANO, Geraldo; LUCIANO, Débora. Novo Código de Defesa Florestal comentado. 1. ed. Rio de Janeiro: LMJ Mundo Jurídico, 2015.

MARCO, Cristhian Magnus De; MEZZAROBA, Orides. O Direito humano ao desenvolvimento sustentável: contornos históricos e conceituais. Revista Veredas do Direito, Belo Horizonte, v. 14, n. 29, p. 232-349, maio/ago. 2017. Disponível em: <http://www. domhelder.edu.br/revista/index.php/veredas/article/view/1066/623>. Acesso em: 22 abr. 2018.

MOLINARO, Carlos Alberto. Interdição da retrogradação ambiental: reflexões sobre um princípio. In: BRASIL; SENADO FEDERAL; COMISSÃO DE MEIO AMBIENTE, DEFESA DO CONSUMIDOR E FISCALIZAÇÃO E CONTROLE (CMA). Princípio da Proibição de Retrocesso Ambiental. Brasília: Senado Federal, 2012. Disponível em: <http://www2.senado.leg.br/bdsf/item/id/242559>. Acesso em 22 abr. 2018.

PRIEUR, Michel. O princípio da proibição de retrocesso ambiental. In: BRASIL; SENADO FEDERAL; COMISSÃO DE MEIO AMBIENTE, DEFESA DO CONSUMIDOR E FISCALIZAÇÃO E CONTROLE (CMA). Princípio da Proibição de Retrocesso Ambiental. Brasília: Senado Federal, 2012. Disponível em: <http://www2.senado.leg.br/bdsf/item/id/242559>. Acesso em: 22 abr. 2018.

ROCHA, Anacélia Santos et al. O dom da produção acadêmica: manual de normalização e metodologia de pesquisa. Belo Horizonte: Escola Superior Dom Helder Câmara, 2017. Disponível em: <http://domhelder.edu.br/uploads/pesquisa/domdaproducaoacademica.pdf>. Acesso em: 22 abr. 2018.

SAMPAIO, José Adércio Leite; WOLD, Chris; NARDY, Afrânio José Fonseca. Princípios de Direito Ambiental na dimensão internacional e comparada. Belo Horizonte: Del Rey, 2003.

SARLET, Ingo Wolfgang. A eficácia dos direitos fundamentais. Porto Alegre: Livraria do Advogado, 2001.

SARLET, Ingo Wolfgang; FENSTERSEIFER, Tiago. Direito Constitucional Ambiental: constituição, direitos fundamentais e proteção do ambiente. 3. ed. rev. atual. ampl. São Paulo: Revista dos Tribunais, 2013.

. Notas sobre a proibição de retrocesso em matéria (socio) ambiental. In: BRASIL; SENADO FEDERAL; COMISSÃO DE MEIO AMBIENTE, DEFESA DO CONSUMIDOR E FISCALIZAÇÃO E CONTROLE (CMA). Princípio da Proibição de Retrocesso Ambiental. Brasília: Senado Federal, 2012. Disponível em: <http://www2.senado.leg.br/bdsf/item/id/242559>. Acesso em: 22 abr. 2018.

SILVA, L. J. S.; EL-DEIR, S. G.; SILVA, R. G. Princípios da sustentabilidade no planejamento socioambiental do Comitê Ecos de Pernambuco. Revista Veredas do Direito, Belo Horizonte, v. 14, n. 30, p. 215-242, set./dez. 2017. Disponível em: <http://www. domhelder.edu.br/revista/index.php/veredas/article/view/1080/682>. Acesso em: 22 abr. 2018.

THOMÉ, Romeu. O princípio da vedação de retrocesso socioambiental no contexto da sociedade de risco. Salvador: Juspodivm, 2014.

VIEIRA, José Ribas; BRASIL, Deilton Ribeiro. A força normativa dos fatos como ferramenta do ativismo judicial utilizada para alargamento da competência do Supremo Tribunal Federal após a EC 45/04. Revista Verba Juris, Paraíba, ano 6, n. 6, jan./dez. 2007. Disponível em: <periodicos.ufpb.br/index.php/vj/article/download/14869/8424>. Acesso em: 22 abr. 2018. 